\title{
Rates and causes of 30-day readmission and emergency room utilization following head and neck surgery
}

\author{
Vincent $\mathrm{Wu}^{1}$ and Stephen F. Hall ${ }^{*}$
}

\begin{abstract}
Background: Unplanned returns to hospital are common, costly, and potentially avoidable. We aimed to investigate and characterize reasons for all-cause readmissions to hospital as in-patients (IPs) and visits to the Emergency Department (ED) within 30-days following patient discharge post head and neck surgery (HNS).

Methods: Retrospective case series with chart review. All patients within the Department of Otolaryngology - Head and Neck Surgery who underwent HNS for benign and malignant disease from January 1, 2010 to May 31, 2015 were identified. The electronic medical records of readmitted patients were reviewed for reasons of readmission, demographic data, and comorbidities.

Results: Following 1281 surgical cases, there were 41 (3.20\%) IP readmissions and 109 (8.43\%) ED visits within 30days after discharge for HNS. For IP readmissions, most common causes included infection (26.8\%), respiratory symptoms (17.1\%), and pain (17.1\%). Most common reasons for ED visits were for pain (31.5\%), bleeding (17.6\%), and infection (14.8\%). Readmitted IPs had significantly higher health burden at pre-operative baseline as compared to patients who visited the ED when assessed with the American Society of Anesthesiology scores $(p=0.002)$ and the Cumulative IIIness Rating Scale $(p=0.004)$.

Conclusion: Rate of 30-day IP readmission and ED utilization was 3.20 and $8.43 \%$, respectively. Pain and infection were common causes for returns to hospital. Discharge planning may be improved to target common causes for post-surgical hospital visits in order to decrease readmission rates.
\end{abstract}

Keywords: Rates, Causes, 30-day, Readmission, Emergency department, Otolaryngology, Head and neck surgery

\section{Background}

Unplanned returns to hospital, including readmissions as in-patients (IPs) and visits to the Emergency Department (ED) are identified as costly, common, and potentially avoidable with proper planning and patient education [1-6]. The Canadian Institute for Health Information (CIHI) identified 30-day readmission rates to be a measure of a hospital's quality and patient care [6]. From its 2012 report, surgical patients were identified as having the second highest overall rate of readmission as IP and return to the ED, contributing to the $\$ 1.8$ billion dollar annual cost associated with 30-day readmissions

\footnotetext{
* Correspondence: steve@sfhallmd.com

${ }^{2}$ Department of Otolaryngology - Head and Neck Surgery, Queen's Cancer Research Institute, Queen's University, 10 Stuart St, Level 2, Kingston, ON K7L 3N6, Canada

Full list of author information is available at the end of the article
}

in Canada [6]. While studies having indicated that between 9 to $59 \%$ of all unplanned readmissions are potentially avoidable, identifying these causes are necessary in order to reduce rates and the associated healthcare spending $[5,7-10]$.

In general, it is known that readmitted patients are older and have more medical comorbidities [11-13]. Being from a low socioeconomic class and having had previous unplanned visits to hospital also increase the risk for readmissions [11, 12, 14]. Moreover, the causes for readmission differ based on the specific patient population $[15,16]$. Studies on surgery patients have identified risk factors for unplanned readmission that differ from medical patients [16]. Within the field of Otolaryngology - Head and Neck Surgery, the surgical procedures performed are diverse in nature. A single

(C) The Author(s). 2018 Open Access This article is distributed under the terms of the Creative Commons Attribution 4.0 International License (http://creativecommons.org/licenses/by/4.0/), which permits unrestricted use, distribution, and 
readmission rate is not representative of the specialty as a whole, and can range from 2 to $8 \%$ depending on the subspecialty focus $[17,18]$. Patients who undergo head and neck surgery (HNS) have been shown to have higher rates of 30-day ED utilization and readmission as IPs [18-20].

Causes for unplanned readmission following HNS have not been thoroughly identified within a Canadian population. Our objective was to analyze and characterize the rates and reasons for all-cause readmission as IP and visits to the ED within 30-days following HNS. The results may serve to potentially reduce readmission rates by acting on preventable causes.

\section{Methods}

\section{Study design and population}

Retrospective chart review was performed of patients who were readmitted as IP or visited the ED within 30days following discharge post-HNS from a tertiary academic center from January 1, 2010 to May 31, 2015. Patients were identified using CIHI procedural codes from hospital-based datasets. Patient cases were separated based on the procedure performed, which were separated into procedural categories. Examples of surgeries performed with procedural categories are shown in Table 1. Procedures pertaining to the nasal cavity, paranasal sinuses, skull base, ears, tonsils, adenoids or skin were not included.

\section{Definition and study variables}

We defined 30-day readmission as an IP admission to hospital for any cause, regardless of assignment under the Department of Otolaryngology - Head and Neck Surgery or another clinical service, within 30-days following initial post-HNS discharge. ED utilization was

Table 1 Included procedural categories

\begin{tabular}{ll}
\hline Procedure Categories & Example \\
\hline Major Head and Neck with No Flap & $\begin{array}{l}\text { Laryngectomy without flap } \\
\text { reconstruction }\end{array}$ \\
$\begin{array}{ll}\text { Major Head and Neck with Pedicled } & \text { Oropharyngeal resection with } \\
\text { pectoralis myocutaneous rotation } \\
\text { flap reconstruction }\end{array}$ \\
Major Head and Neck with Free Flap & $\begin{array}{l}\text { Excision of oropharynx with } \\
\text { radial forearm free flap } \\
\text { reconstruction }\end{array}$ \\
Open Airway & $\begin{array}{l}\text { Tracheostomy } \\
\text { Limited Oral Cavity }\end{array}$ \\
Limited Neck & Branchial cleft cyst resection \\
Neck Dissection Only & Cervical lymph node dissection \\
Salivary Gland & Parotidectomy \\
Thyroid/Parathyroid & Total thyroidectomy \\
\hline
\end{tabular}

defined as any visit to the ED within 30-days following post-HNS discharge.

The primary outcome measure was causes for 30-day IP readmission, extracted as the primary diagnosis from electronic hospital discharge summaries. Secondarily, we evaluated causes for ED utilization, extracted from ED charts as the final diagnosis. If more than one ED visit or IP admission was noted within the 30-day period following surgery, only the first readmission/visit was recorded.

Additionally, patient demographics including age and sex were captured. The American Society of Anesthesiologists (ASA) score, admission date, procedure date, initial discharge date, and return date were also included. Patient comorbidities were captured using the Cumulative Illness Rating Scale (CIRS), which is a validated summative index aimed at quantifying the overall physical impairment of the patient through 13 independent organ system domains, with higher scores indicating greater comorbid illness [21].

\section{Statistical analysis}

All statistical analyses were performed using Prism (v7.0, GraphPad, La Jolla, CA, USA) and statistical significance was set to $\alpha=0.05$. Results are reported as mean \pm standard deviation (SD). Standard descriptive statistics were used to characterize causes for readmission. Patient information including age, gender, sex, comorbidities, ASA score were also described using descriptive statistics. Student's t-tests were performed to compare differences in ASA and CIRS among IPs and ED patients.

\section{Results}

Of the 1281 patients who underwent HNS during the study period, $120(9.37 \%)$ patients returned to hospital within 30-days of discharge. In total, there were 41 (3.20\%) IP readmissions and 108 (8.43\%) ED visits. There were 29 patients who were admitted as IPs through the ED. Patient demographics are summarized in Table 2.

Table 2 Baseline Patient Characteristics

\begin{tabular}{ll}
\hline Variable & Included $(n=120)$ \\
\hline Age (mean \pm SD years) & $57.5 \pm 20.7$ \\
Male $(n, \%)$ & $78,65 \%$ \\
Length of stay (mean \pm SD days) & $7.58 \pm 17.1$ \\
CIRS (mean \pm SD) & $5.15 \pm 3.44$ \\
ASA (mean \pm SD) & $2.82 \pm 0.83$ \\
Previous radiotherapy $(n, \%)$ & $9,7.5 \%$ \\
Previous chemotherapy $(n, \%)$ & $2,1.7 \%$ \\
Previous chemoradiation therapy $(n, \%)$ & $7,5.8 \%$
\end{tabular}

*SD - standard deviation 
Table 3 Rates and causes of in-patient admissions

\begin{tabular}{lll}
\hline Causes & Numbers & Rates \\
\hline Infection: UTI, sepsis & 11 & $26.83 \%$ \\
Respiratory: COPDE, dyspnea & 7 & $17.07 \%$ \\
Pain: surgical/graft site & 7 & $17.07 \%$ \\
Systemic: dehydration & 7 & $17.07 \%$ \\
Neurologic: seizures & 3 & $7.31 \%$ \\
Bleeding: surgical site & 3 & $7.31 \%$ \\
Exacerbation of chronic condition & 2 & $4.87 \%$ \\
Cardiac: chest pain & 1 & $2.43 \%$ \\
\hline
\end{tabular}

*UTI - urinary tract infection; COPDE; chronic obstructive pulmonary disease exacerbation

Causes for readmission to hospital as IPs are listed in Table 3. The single most common reason for IP readmission was for infection $(26.8 \%)$, which included sepsis, surgical site infection, and urinary tract infection. Reasons for visiting the ED are listed in Table 4, with the most common cause being pain at the surgical site $(31.5 \%)$.

The CIRS comorbidity score in patients who were readmitted as IPs $(6.29 \pm 3.27)$ were significantly higher than patients who visited the ED (4.56 \pm 3.39$)$, $p=0.004$. This was similarly seen with the ASA score, with readmitted IPs $(3.12 \pm 0.64)$ having significantly higher scores compared to patients visiting the ED $(2.66 \pm 0.88), p=0.002$. A simple linear regression of ASA and CIRS scores revealed a significant positive correlation between the measures, $F(1,118)=73.37$, $p<0.001$, with an $r^{2}=0.383$.

\section{Discussion}

This descriptive study highlighted the rates and causes of 30-day readmission following HNS for benign and malignant causes within a Canadian tertiary academic center. Although 30-day readmission rates have been

Table 4 Rates and causes of Emergency Department visits

\begin{tabular}{lll}
\hline Causes & Numbers & Rates \\
\hline Pain: surgical/graft site & 34 & $31.48 \%$ \\
Bleeding: surgical/graft site & 19 & $17.59 \%$ \\
Infection: surgical/graft site, UTI & 16 & $14.81 \%$ \\
Equipment: nasogastric tube, tracheostomy & 8 & $7.41 \%$ \\
tube, surgical drain & & \\
Cardiac: chest pain, syncope & 7 & $6.48 \%$ \\
Respiratory: dyspnea & 7 & $5.48 \%$ \\
Gastrointestinal: nausea/vomit, constipation & 6 & $4.63 \%$ \\
Neurologic: seizure, weakness & 5 & $3.70 \%$ \\
Exacerbation of chronic condition & 4 & $1.85 \%$ \\
Psychiatric: delirium & 2 & \\
\hline
\end{tabular}

*UTI - urinary tract infection used as a quality metric for hospital care, there are limitations to its use. While potentially preventable causes for readmission exist, there are factors which are nonmodifiable that can contribute to patient readmission and hospital utilization. These factors include patient gender, race, socioeconomic status, and comorbidities [15]. Causes of readmission also differ based on the specific patient population. Therefore, by examining a subspecialty population such as patients who underwent HNS, the specific needs of that group may be identified. Although truly preventable causes of 30-day readmission are low given various non-modifiable factors, this study ultimately identified common reasons for hospital visits such as pain and infection, which we believe may be preventable with changes made to discharge planning and improved patient education.

The rate of IP readmission among post-HNS patient was found to be $3.20 \%$ within our cohort. This is below the $5.1-14.5 \%$ readmission rate currently reported for HNS patients in the United States [19, 20, 22]. Compared to the study by Bur et al. who examined risk factors and causes for readmissions within HNS for malignant causes, our IP readmission numbers were lower [19]. This may be due to the incorporation of patients undergoing HNS for benign causes within our study. Similar causes for readmissions were noted within our cohort, with infection being the most common, followed by respiratory causes and dehydration [19]. In terms of risk factors, Bur et al. noted the presence of medical comorbidities such as diabetes and dyspnea at baseline were associated with increased readmission [19]. Although we did not capture specific comorbidities, we noted that increased ASA and CIRS were higher for IP readmitted patient as compared with patients who visited the ED only. Together, our results reaffirm that infectious and respiratory symptoms are common causes for readmission, and that readmitted IPs patients have increased baseline disease burden and comorbidities. Furthermore, our results revealed potentially preventable causes for readmission such as dehydration, which may be linked to altered diets, inadequate pain control, and/ or poor oral intake, all of which may be optimized prior to discharge.

Literature surrounding ED utilization have mainly focused on specific procedures, not HNS as a whole. One study reported ED utilization after thyroidectomy and parathyroidectomy to be $11.22 \%$, with common causes being paresthesia and wound complications [23]. Within our cohort, we noted an ED utilization rate of $8.43 \%$, with the most common cause due to pain. To us, this represented a preventable cause of hospital utilization that may be better improved with discharge planning and patient education. As discharge is a transition time from hospital to home, many patients may feel 
inadequately prepared based on the information received in hospital [24]. Specific interventions including early discharge planning and individualized education can potentially reduce readmissions and ED utilization by $75 \%$ [25-27]. Moreover, noting the pain trajectories and addressing those patients with high pain levels prior to discharge may help to further decrease ED utilization [28]. Ultimately, systems analysis of discharge planning can be used to identify various steps associated with patient discharge including the delivery of information, and the type and amount of information that is delivered to the patient, in order to optimize the process.

ASA status has been reported to have a significant positive associated with higher readmission rates, and was among the variables strongly associated with predicting readmissions [13]. CIRS has also been used among HNS patients, with higher scores reflective of worsening health burden for an individual $[21,29]$. This suggested that IPs were sicker and had increased health burden at baseline, which may have predisposed them to more frequent and serious medical complications requiring in-hospital admission. Often, procedures within HNS involve the resection of head and neck cancers. It is known that head and neck cancer patients have more medical comorbidities, often resulting from chronic exposures to risk factors such as tobacco and alcohol [30-33]. Therefore, it is not surprising that with potential increases in risk factor exposure that we noted higher ASA and CIRS scores among patients who were readmitted as IPs.

Currently, the distinction between surgical and medical causes for post-operative complications is still unclear. Even for surgical complications, there is still no agreed upon definition [34]. Common methods for categorizing post-operative complications, including the Clavien-Dindo Classification, makes no distinction made between medical and surgical causes [35]. There have been attempts to separate readmission based on surgical complications (bleeding, wound dehiscence, and surgical site infection) from other medical complications [36]. However, the inherent limitation of this approach is that the exacerbation of medical comorbidities, or development of new medical conditions, may be a result of the surgical stress. The standardization of post-operative complications will be helpful in distinguishing between complications as a result of the surgical procedure versus an exacerbation of a pre-existing medical condition due to the general stresses of surgery. This will be important for eliciting preventable surgical causes aimed at decreasing the overall readmission rate.

This study has potential limitations. First, inherent to retrospective chart reviews, there exists the possibility of selection bias. A preliminary list of patients who returned to hospital within 30-days following head and neck surgery was generated automatically through the hospital's centralized patient information database. To ensure validity of the extracted data, individual chart review was conducted by the study author (V.W.) only after extensive training on the electronic medical record. The senior author (S.F.H.) oversaw the data extraction with periodic reviews. Additionally, information was not extracted for patients who did not have a 30-day readmission or ED visit, thereby preventing risk assessment and comparisons being drawn between this group and patients who had a readmission. Moreover, data was not available for the rates of ED and IP readmission in regional hospitals for the same procedures, precluding the ability to compare readmissions rates outside of our academic center. Our sample size was limited by some of these factors, and as such, an increased study size can potentially address some of this study's limitations. Future prospective studies can also aim to account for these potential limitations and utilize additional metrics for hospital and patient quality of care including patientreported outcomes and length of stay.

\section{Conclusion}

The 30-day IP readmission rate for post HNS patients was $3.20 \%$ and the ED utilization rate was $8.43 \%$. Pain and infection represented common causes for returns to hospital. Discharge planning may be improved to target common causes for post-surgical readmission as potential steps in decrease hospital readmission and ED visit rates.

\section{Abbreviations \\ ASA: American Society of Anesthesiologists; CIHI: Canadian Institute for Health Information; CIRS: Cumulative Illness Rating Scale; COPD: Chronic obstructive pulmonary disease; ED: Emergency Department; HNS: Head and neck surgery; IP: In-patient; SD: Standard deviation}

\section{Acknowledgements}

1. This study was presented as a podium presentation at the Canadian Society of Otolaryngology - Head and Neck Surgery annual meeting in Charlottetown, Prince Edward Island, 2016.

2. The authors would like to thank David Barber, Decision Support, Kingston

General Hospital, for generating the patient list.

3. The authors would like to thank Susan Rohland, Cancer Care and

Epidemiology, Queen's University, for coordinating the study.

\section{Funding}

This research was funded by the Department of Otolaryngology - Head and Neck Surgery, Queen's University, Kingston, Ontario.

\section{Availability of data and materials}

The datasets generated and analysed during the current study are available from the corresponding author on reasonable request.

\section{Authors' contributions}

All authors were involved with the conception and design of the study, analysis and interpretation of data, revision of the manuscript, and have approved the final manuscript.

Ethics approval and consent to participate

This study was approved by the Queen's University Health Sciences and Affiliated Teaching Hospitals Research Ethics Board (\#6010995). 


\section{Competing interests}

The authors declare that they have no competing interests.

\section{Publisher's Note}

Springer Nature remains neutral with regard to jurisdictional claims in published maps and institutional affiliations.

\section{Author details}

'School of Medicine, Faculty of Health Sciences, Queen's University, 80 Barrie St, Kingston, ON K7L 3J8, Canada. ${ }^{2}$ Department of Otolaryngology - Head and Neck Surgery, Queen's Cancer Research Institute, Queen's University, 10 Stuart St, Level 2, Kingston, ON K7L 3N6, Canada.

\section{Received: 23 November 2017 Accepted: 7 May 2018}

Published online: 18 May 2018

\section{References}

1. Jencks SF, Williams MV, Coleman EA. Rehospitalizations among patients in the Medicare fee-for-service program. N Engl J Med. 2009;360:1418-28.

2. Soeken KL, Prescott PA, Herron DG, Creasia J. Predictors of Hospital Readmission: A Meta-Analysis. Eval Health Prof. 1991;14(3):262-81.

3. Vest JR, Gamm LD, Oxford BA, Gonzalez MI, Slawson KM. Determinants of preventable readmissions in the United States: a systematic review. Implement Sci. 2010;5:88.

4. Anderson GF, Steinberg EP. Hospital readmissions in the Medicare population. N Engl J Med. 1984;311(21):1349-53.

5. Frankl SE, Breeling JL, Goldman L. Preventability of emergent hospital readmission. Am J Med. 1991;90(6):667-74.

6. All-cause readmission to acute care and return to the emergency department. Ottawa: Canadian Institute for Health Information; 2012.

7. Clarke A. Are Readmissions Avoidable? BMJ. 1990;301(6761):1136-8.

8. Graham H, Livesley B. Can readmissions to a geriatric medical unit be prevented? Lancet. 1983;1(8321):404-6.

9. Halfon P, Eggli Y, van Melle G, Chevalier J, Wasserfallen JB, Burnand B. Measuring potentially avoidable hospital readmissions. J Clin Epidemiol. 2002:55(6):573-87

10. Oddone EZ, Weinberger M, Horner M, Mengel C, Goldstein F, Ginier P, et al. Classifying general medicine readmissions: are they preventable? Veterans affairs cooperative studies in health services group on primary care and hospital readmissions. J Gen Intern Med. 1996;11(10):597-607.

11. van Walraven C, Dhalla IA, Bell C, Etchells E, Stiell IG, Zarnke K, et al. Derivation and validation of an index to predict early death or unplanned readmission after discharge from hospital to the community. CMAJ. 2010; 182(6):551-7.

12. Boult C, Dowd B, McCaffrey D, Boult L, Hernandez R, Krulewitch H. Screening elders for risk of hospital admission. J Am Geriatr Soc. 1993;41(8): 811-7.

13. Merkow RP, Ju MH, Chung JW, Hall BL, Cohen ME, Williams MV, et al. Underlying reasons associated with hospital readmission following surgery in the United States. JAMA. 2015;313(5):483-95.

14. Weissman JS, Stern RS, Epstein AM. The impact of patient socioeconomic status and other social factors on readmission: a prospective study in four Massachusetts hospitals. Inquiry. 1994;31(2):163-72.

15. Benbassat J, Taragin M. Hospital readmissions as a measure of quality of health CareAdvantages and limitations. Arch Intern Med. 2000:160(8):1074-81

16. Kassin MT, Owen RM, Perez S, Leeds I, Cox JC, Schnier K, et al. Risk factors for 30-day hospital readmission among general surgery patients. J Am Coll Surg. 2012;215:322-30

17. Graboyes EM, Liou TN, Kallogjeri D, Nussenbaum B, Diaz JA. Risk factors for unplanned hospital readmission in otolaryngology patients. Otolaryngol Head Neck Surg. 2013;149(4):562-71.

18. Jain U, Chandra RK, Smith SS, Pilecki M, Kim JY. Predictors of readmission after outpatient otolaryngologic surgery. Laryngoscope. 2014;124(8):1783-8.

19. Bur AM, Brant JA, Mulvey CL, Nicolli EA, Brody RM, Fischer JP, Cannady SB, Newman JG. Association of clinical risk factors and postoperative complications with unplanned hospital readmission after head and neck cancer surgery. JAMA Otolaryngol Head Neck Surg. 2016;142(12):1184-90.

20. Offodile AC, II, Pathak A, Wenger J, Orgill DP, Guo L. Prevalence and patientlevel risk factors for 30-day readmissions following free tissue transfer for head and neck Cancer. JAMA Otolaryngol Head Neck Surg. 2015;141(9):783-789.

21. Linn BS, Linn MW, Gurel L. Cumulative illness rating scale. J Am Geriatr Soc. 1968;16(5):622-6.

22. Dziegielewski PT, Boyce B, Manning A, Agrawal A, Old M, Ozer E, Teknos TN. Predictors and costs of readmissions at an academic head and neck surgery service. Head Neck. 2016;38(Suppl 1):E502-10.

23. Young WG, Succar E, Hsu L, Talpos G, Ghanem TA. Causes of emergency department visits following thyroid and parathyroid surgery. JAMA Otolaryngol Head Neck Surg. 2013 Nov 1;139(11):1175-80.

24. Zeng-Treitler Q, Kim H, Hunter M. Improving patient comprehension and recall of discharge instructions by supplementing free texts with pictographs. AMIA Annu Symp Proc. 2008;2008:849-53.

25. Evans RL, Hendrick RD. Evaluating hospital discharge planning: a randomized clinical trial. Med Care. 1993:31:358-70.

26. Jack BW, Chetty VK, Anthony D, Greenwald JL, Sanchez GM, et al. A reengineered hospital discharge program to decrease rehospitalization: a randomized trial. Ann Intern Med. 2009;150:178-87.

27. Coleman EA, Parry C, Chalmers S, Min S. The care transitions intervention: results of a randomized controlled trial. Arch Intern Med. 2006;166:1822-8.

28. Hernandez-Boussard T, Graham LA, Desai K, Wahl TS, Aucoin E, Richman JS, et al. The fifth vital sign: postoperative pain predicts 30-day readmissions and subsequent emergency department visits. Ann Surg. 2017;266(3):516-24.

29. Castro MA, Dedivitis RA, Ribeiro KC. Comorbidity measurement in patients with laryngeal squamous cell carcinoma. ORL J Otorhinolaryngol Relat Spec. 2007;69(3):146-52.

30. Hashibe M, Brennan P, Benhamou S, Castellsague X, Chen C, Curado MP, et al. Alcohol drinking in never users of tobacco, cigarette smoking in never drinkers, and the risk of head and neck cancer: pooled analysis in the international head and neck Cancer epidemiology consortium. J Natl Cancer Inst. 2007;99(10):777-89.

31. Blot WJ, McLaughlin JK, Winn DM, Austin DF, Greenberg RS, Preston-Martin $\mathrm{S}$, et al. Smoking and drinking in relation to oral and pharyngeal cancer Cancer Res. 1988:48(11):3282-7.

32. Hashibe M, Boffetta P, Zaridze D, Shangina O, Szeszenia-Dabrowska N, Mates D, et al. Evidence for an important role of alcohol- and aldehydemetabolizing genes in cancers of the upper aerodigestive tract. Cancer Epidemiol Biomark Prev. 2006:15(4):696-703.

33. Gandini S, Botteri E, lodice S, Boniol M, Lowenfels AB, Maisonneuve P, et al. Tobacco smoking and cancer: a meta-analysis. Int J Cancer. 2008;122(1):155-64.

34. Sokol DK, Wilson J. What is a surgical complication? World J Surg. 2008; 32(6):942-4.

35. Dindo D, Demartines N, Clavien PA. Classification of surgical complications: a new proposal with evaluation in a cohort of 6336 patients and results of a survey. Ann Surg. 2004;240(2):205-13.

36. Graboyes EM, Kallogjeri D, Saeed MJ, Olsen MA, Nussenbaum B. 30-day hospital readmission following otolaryngology surgery: analysis of a state inpatient database. Laryngoscope. 2017;127(2):337-45.

\section{Ready to submit your research? Choose BMC and benefit from:}

- fast, convenient online submission

- thorough peer review by experienced researchers in your field

- rapid publication on acceptance

- support for research data, including large and complex data types

- gold Open Access which fosters wider collaboration and increased citations

- maximum visibility for your research: over $100 \mathrm{M}$ website views per year

At BMC, research is always in progress.

Learn more biomedcentral.com/submissions 